Original Article

\title{
Chronic Kidney Disease in Police Forces Households in Khartoum, Sudan: Pilot Report
}

Part of the Police Forces Hypertension, Diabetes, Renal Insufficiency and Thyroid Derangement (HyDRIT) study, Sudan

\author{
Hasan Abu-Aisha ${ }^{\mathrm{a}}$, Elwaleed AM Elhassan ${ }^{\mathrm{b}}$, Ammar Hasan Khamis ${ }^{\mathrm{c}}$, Adil Abu-Elmaali ${ }^{\mathrm{d}}$ \\ a. Consultant physician and nephrologist, National Ribat University Hospital \\ b. Assistant prof. of internal medicine, University of Khartoum \\ c. Associate prof. of biostatistics, Sudan University for Science and Technology \\ d. Head department of community medicine, National Ribat University
}

\begin{abstract}
Introduction: In the Police Forces Hypertension, Diabetes, Renal Insufficiency and Thyroid Derangement (HyDRIT) pilot study we explored the prevalence, risk factors, awareness, treatment adequacy and complications of chronickidney disease(CKD) and othernon-communicable diseases among adult Police Forces households in two housing complexes in Khartoum, Sudan.
\end{abstract}

Methods: Serum creatinine measurements and urine dipstick testing were performed for 273 individuals. The glomerular filtration rate (GFR) was estimated using the standardized Cockroft-Gault and the four variable MDRD formulas. CKD was defined as an estimated GFR of less than $60 \mathrm{ml} / \mathrm{min} / 1.73 \mathrm{~m} 2$ and/or proteinuria.

Results: The overall prevalence of CKD was 11\% (30/273) using the standardized Cockroft-Gault equation and $7.7 \%(21 / 273)$ using the four variable MDRD equation. According to the standardized Cockroft-Gault formula, 14 subjects had reduced GFR with negative urine dipstick testing, two subjects had both proteinuria and reduced GFR, and 14 subjects had proteinuria without reduction in GFR. None of those subjects was aware of his kidney problem. According to the standardized Cockroft-Gault formula, 14 of the identified CKD cases were hypertensive (46.7\%); eight of them (57.1\%) had a prior diagnosis of hypertension but none achieved therapeutic targets. Four of the identified CKD cases were diabetic (13.3\%), three of whom had a prior diagnosis of diabetes mellitus with reasonably controlled blood sugar levels. Only age above 50 years and low educational level proved to be independent risk factors for CKD in multivariate analysis.

Conclusion: The prevalence of CKD in the study population seems to be comparable to other countries.

\footnotetext{
* Corresponding author; Division of Renal Diseases and Hypertension, University of Colorado Health Sciences Center, P.O.Box 6508, Aurora, CO 80045, USA; E mail: Elwaleed.Elhassan@UCHSC.edu
}

Keywords: awareness, chronic kidney disease, diabetes mellitus, hypertension, prevalence, Sudan

\section{Introduction}

Chronic kidney disease (CKD) is emerging as a global threat to human health. Screening surveys of representative samples of the whole population performed in the US, Australia, Japan and Europe have identified between $6 \%$ and $11 \%$ as having some degree of CKD [1-4]. Population-based studies relating to the prevalence of CKD in developing countries are scarce. Several studies have demonstrated high incidence of CKD among black Americans. Unfortunately, there are no reliable statistics on CKD from most African countries. However, there is a general impression that it is at least three to four times more frequent than in developed countries [5]. The number of patients with end stage renal disease (ESRD) probably underestimates the entire burden of CKD because the numbers with earlier stages of disease are likely to exceed by as much as 50 times those reaching ESRD [1].

With the rising prevalence of its risk factors, CKD has become increasingly common. Diabetes mellitus (DM) and hypertension are major risk factors for renal function impairment. The association of renal disease and certain social and economic factors suggests that lack of timely preventive health care interventions focused on these factors may aggravate this problem. Individuals whose disease progresses are not only faced by the need for dialysis, kidney transplantation and shortened life expectancy, but are also at very high risk for cardiovascular disease $[6,7]$.

The global total cumulative cost for renal replacement therapy is 1 trillion US \$. The cost and complexity of renal replacement therapy make it challenging for developing countries, which are struggling to provide preventive and 
therapeutic measures for communicable diseases such as malaria, tuberculosis, AIDS and other tropical infections. Once recognized, simple and inexpensive treatments to manage the early stages of CKD proved effective to slow down its progression. In Sudan, there is no national registry for renal patients and the knowledge about the epidemiology of CKD is very limited.

In this article, we display the results of the CKD survey of the Hypertension, Diabetes, Renal Insufficiency and Thyroid Derangement (HyDRIT) pilot study in Sudan. This study was designed as a limited population-based survey of the prevalence of some non-communicable diseases and their underlying risk factors. The general objective of this study was to provide insight about the awareness, prevalence, risk factors, treatment adequacy and complications of CKD and other non-communicable diseases among a large sample of Sudanese police forces households who are probably representative of the Sudanese population.

\section{Methods}

This was a pilot cross-sectional community-based survey of police housing complexes in Greater Khartoum (comprising three cities; Khartoum, Omdurman and Khartoum North). The protocol was approved by the ethics committee of the National Ribat University.

Khartoum is the capital city of Sudan with about 6 million inhabitants. Police housing complexes are scattered throughout the city. They are co-inhabited by Police officers and soldiers as well as their immediate, and many times, extended family members. They reflect people with average Sudanese characteristics regarding income and baseline demographics. They are entitled to free medical service, mainly provided at the Central Police Hospital in Khartoum. The estimated total number of inhabitants is seven thousands residing in 26 complexes. Phase one of the study was undertaken in the first two of these complexes, targeting about 436 individuals. All houses were visited and all inhabitants more than 18 years of age were asked to participate.

The field visits were conducted by the senior students of the National Ribat University Medical School during October 2005. Prior to the study, students underwent planned training to follow a standardized protocol for administering the questionnaire, measuring blood pressure and anthropometric parameters and blood sampling. Experienced laboratory technicians were available to help with blood draws. Students were divided into teams of two to fill out the questionnaire and carry out relevant tests. Monitoring of compliance with the above procedures was regularly conducted by a physician and a social worker who frequently oversaw executing teams.

Informed consent was obtained from participants prior to recruitment. All participants underwent a standard interview to record demographic and lifestyle characteristics as well as the presence of hypertension, DM, and renal disease. Study participants with hypertension or DM were asked whether they were using, and if so compliant with, prescribed medications.

Blood pressure was measured using a sphygmomanometer with the subject seated in a chair with his arm at the level of the heart. Standard mercury sphygmomanometers were used, and one of two cuff sizes (regular adult or large) were chosen based on the circumference of the participant's arm. Systolic and diastolic blood pressure was considered as Korotkoff's phases 1 and 5 respectively. Two measurements were taken with at least 2 minutes interval between them and the average of both systolic and diastolic blood pressures was recorded. Hypertension was defined as systolic blood pressure (SBP) $\geq 140 \mathrm{mmHg}$, and/or diastolic blood pressure (DBP) $\geq 90 \mathrm{mmHg}$, and/ or current use of antihypertensive medications. Control of hypertension was defined as SBP less than $130 \mathrm{mmHg}$ and DBP less than $80 \mathrm{mmHg}$. Underweight was defined as body mass index (BMI) less than $18.5 \mathrm{~kg} / \mathrm{m} 2$, normal weight as BMI 18.5-24.9 $\mathrm{kg} / \mathrm{m}^{2}$, overweight as BMI $25-29.9 \mathrm{~kg} / \mathrm{m}^{2}$, and obesity as BMI $\geq 30 \mathrm{~kg} / \mathrm{m}^{2}$.

Participants were requested to give blood and midstream urine samples for analysis. Samples were transported to the central laboratory of the National Ribat University Hospital (RUH) for processing. Urine samples were tested for proteins and red blood cells with standard dipsticks. Proteinuria was considered present if a subject had one or more crosses of protein. Blood samples were analyzed for serum creatinine, blood sugar and serum cholesterol levels.

The glomerular filtration rate (GFR) was estimated using the Cockroft-Gault formula standardized for body surface area (BSA) and the four variable MDRD study equation. BSA was calculated according to Dubois and Dubois formula. CKD was defined as an estimated GFR of less than $60 \mathrm{ml} / \mathrm{min} / 1.73 \mathrm{~m}^{2}$ and/or proteinuria. DM was considered present if random blood glucose level was $\geq$ $200 \mathrm{mg} / \mathrm{dl}$ [8] or if the patient had a prior diagnosis of diabetes. Hypercholesterolemia was defined as random serum cholesterol $\geq 200 \mathrm{mg} / \mathrm{dl}$.

Subjects found to have any of the above conditions were referred to RUH for follow-up. A special clinic was arranged to accommodate the HyDRIT study participants and care was provided free of charge. 
Table 1: Comparison of the prevalence of the five NKF-KDOQI GFR categories in our study population and the US adult population [1]

\begin{tabular}{llll}
\hline $\begin{array}{l}\text { Estimated GFR } \\
\left(\mathbf{m l} / \mathbf{m i n} / \mathbf{1 . 7 3} \mathbf{~ m}^{\mathbf{2}}\right)\end{array}$ & $\begin{array}{l}\text { HyDRIT study (\%) } \\
\text { Cockroft-Gault formula }\end{array}$ & $\begin{array}{l}\text { HyDRIT study (\%) } \\
\text { MDRD formula }\end{array}$ & $\begin{array}{l}\text { US population (\%) } \\
\text { MDRD formula }\end{array}$ \\
\hline$\geq 90$ & 63 & 65.6 & 64.3 \\
$60-89$ & 31.1 & 31.5 & 31.2 \\
$30-59$ & 5.5 & 2.6 & 4.3 \\
$15-29$ & 0 & 0 & 0.2 \\
$<15$ & 0.4 & 0.4 & 0.2 \\
\hline
\end{tabular}

Table 2: Comparison of the prevalence of the five NKF-KDOQI CKD stages in our study population and the US adult population [1]

\begin{tabular}{llll}
\hline CKD stage & $\begin{array}{l}\text { HyDRIT study (\%) } \\
\text { Cockroft-Gault formula }\end{array}$ & $\begin{array}{l}\text { HyDRIT study (\%) } \\
\text { MDRD formula }\end{array}$ & $\begin{array}{l}\text { US population (\%) } \\
\text { MDRD formula }\end{array}$ \\
\hline Stage 1 or 2 & 5.1 & 4.7 & 6.3 \\
Stage 3 & 5.5 & 2.6 & 4.3 \\
Stage 4 & 0 & 0 & 0.2 \\
Stage 5 & 0.4 & 0.4 & 0.2 \\
\hline
\end{tabular}

The SPSS software version 15 was used to analyze the data. P values less than 0.05 were considered statistically significant.

\section{Results}

Out of 436 individuals approached, 426 (97.7\%) responded to our questionnaire and had their anthropometric measures and blood pressure recorded. However, because of lack of some subjects' consent and logistic and technical difficulties, only 273 blood and urine samples were available for analysis. In effect, only 273 subjects were surveyed for the presence of CKD, DM and hypercholesterolemia.

Of those 273 individuals, 134 (49.1\%) were males and 139 (50.9\%) were females. The mean age was 34.3 years (SD: 12, range: 18-87). 103 individuals (37.9\%) originally came from the central region of Sudan, 96 $(35.3 \%)$ from the west, $33(12.1 \%)$ from the south, 28 $(10.3 \%)$ from the north, and $12(4.4 \%)$ from the east. Seventy-two individuals (26.7\%) were single whereas the remainder were previously or currently married. Eighty-one individuals $(30.2 \%)$ were policemen and women, 83 (31\%) were housewives and only 13 (4.9\%) were unemployed. The remaining had different jobs; the majority working in private enterprises. Fifteen individuals $(5.5 \%)$ were illiterate, $24(8.8 \%)$ had $1-5$ years of education, $37(13.5 \%)$ had 6-9 years of education while $195(71.4 \%)$ had 10 or more years of education. Thirty
(11\%) were active smokers and $9(3.3 \%)$ were previous smokers; $24(8.8 \%)$ used tumbak (tobacco kept in the buccal mucus membranes for variable lengths of time). Only eight individuals (2.9\%) reported alcohol drinking and none reported using illicit drugs. The prevalence of underweight, overweight and obesity was 9.9\%, 30.4\% and $15.4 \%$ respectively. Only one individual had a heart attack and stroke in the past.

Estimated GFR strata according to the five NKF-KDOQI categories are shown in comparison to US population (Table 1).

The overall prevalence of CKD was $11 \%$ (30/273) using the standardized Cockroft-Gault equation and 7.7\% (21/273) using the four variable MDRD equation. None of those subjects was aware of his kidney problem.

According to the standardized Cockroft-Gault formula, $5.1 \%(14 / 273)$ of subjects had proteinuria with an estimated GFR $\geq 60 \mathrm{ml} / \mathrm{min} / 1.73 \mathrm{~m}^{2}$ (corresponding to stages 1-2 CKD), while 5.9\% (16/273) had an estimated GFR $<60 \mathrm{ml} / \mathrm{min} / 1.73 \mathrm{~m}^{2}$ (corresponding to stages 3-5 $\mathrm{CKD}$ ) including two subjects with proteinuria (Table 2).

According to the MDRD formula, 4.7\% (13/273) of subjects had proteinuria with an estimated GFR $\geq 60 \mathrm{ml} /$ $\mathrm{min} / 1.73 \mathrm{~m}^{2}$ (corresponding to stages $1-2 \mathrm{CKD}$ ), while $2.9 \%(8 / 273)$ had an estimated GFR $<60 \mathrm{ml} / \mathrm{min} / 1.73$ $\mathrm{m}^{2}$ (corresponding to stages 3-5 CKD) including three subjects with proteinuria (Table 2). 
Table 3: Risk factors for CKD using univariate analysis

\begin{tabular}{llll}
\hline Variable & OR & 95 \% C.I. & P value \\
\hline Age above 50 years & 13.5 & $5.1-35.8$ & 0.00 \\
Less than 10 years of education & 5.2 & $2.3-11.6$ & 0.00 \\
Diabetes mellitus & 3.6 & $1.1-12.2$ & 0.05 \\
Hypercholesterolemia & 3.1 & $1.2-7.9$ & 0.03 \\
Underweight & 2.6 & $1-7.2$ & 0.06 \\
Hypertension & 2.4 & $1.1-5.3$ & 0.02 \\
Active smoking & 2.3 & $0.8-6.1$ & 0.09 \\
Male gender & 1.0 & $0.5-2.2$ & 0.53
\end{tabular}

OR: odds ratio, $\mathrm{CI}$ : confidence interval

Table 4: Risk factors for CKD using multinomial logistic regression analysis

\begin{tabular}{llcc}
\hline Variable & OR & 95 \% C.I. & P value \\
\hline Age above 50 years & 5.4 & $1.6-18.4$ & 0.01 \\
Diabetes mellitus & 3.8 & $0.8-19.6$ & 0.12 \\
Less than 10 years of education & 3.0 & $1.1-8.1$ & 0.03 \\
Active smoking & 3.0 & $1.0-9.5$ & 0.06 \\
Underweight & 2.8 & $0.8-9.4$ & 0.09 \\
Hypertension & 1.5 & $0.6-4.0$ & 0.40 \\
Hypercholesterolemia & 1.4 & $0.4-4.9$ & 0.62 \\
Male gender & 1.0 & $0.5-2.2$ & 0.53 \\
\hline
\end{tabular}

OR: odds ratio, $\mathrm{CI}$ : confidence interval

Further analysis of potential risk factors was based on CKD identification by the standardized Cockroft-Gault formula. Fourteen $(46.7 \%)$ of identified CKD cases were hypertensive; eight of them $(57.1 \%)$ had a prior diagnosis of hypertension and seven were on antihypertensive medication. However, none of them had a controlled blood pressure of less than 130/80 $\mathrm{mmHg}$.

Four of identified CKD cases (13.3\%) were diabetic; three of them had a prior diagnosis of DM including two subjects on hypoglycemic agents. All of them had controlled blood sugar levels less than $160 \mathrm{mg} / \mathrm{dl}$.

Fourteen of screened individuals $(5.1 \%)$ were found to be diabetic; eight of them $(57.1 \%)$ had a prior diagnosis of DM, two of whom had their blood sugar controlled by diet, while the other six were on hypoglycemic agents. Only two of the six patients on hypoglycemic agents had blood sugar levels less than $160 \mathrm{mg} / \mathrm{dl}$. Among the 14 diabetic patients, four $(28.6 \%)$ were identified to have CKD including two subjects with proteinuria (14.3\%).

Twenty-nine of screened individuals (10.6\%) had hypercholesterolemia; seven $(24.1 \%)$ of them were identified to have CKD, including two subjects with proteinuria $(6.9 \%)$.

Age above 50 years, low educational level, hypercholesterolemia and hypertension were significantly more common in the CKD group (Table 3). However, only age above 50 years and low educational level proved to be independent risk factors for CKD in multivariate analysis (Table 4).

This pilot study is the first step in a larger study of the prevalence of non-communicable diseases among an estimated seven thousands inhabitants in police housing complexes in Greater Khartoum. Our results show that this sample has prevalence rates of CKD, hypertension and DM similar to those in developed countries with national registries of renal patients [1-4].

The MDRD study equation was developed with the use of data from 1628 patients with CKD and was subsequently validated in numerous populations, including African Americans, Whites, and Asians. It estimates GFR adjusted for body surface area. The MDRD study equation is believed to be more accurate than either the use of the 
Cockcroft-Gault equation or direct measurement of creatinine clearance [10]. For Blacks, the product is multiplied by 1.212 to compensate for a higher average serum creatinine level in Blacks, partly owing to increased muscle mass [10]. Sudan is a large country with diverse ethnicities ranging from Arabs to indigenous Africans. In general, people tend to have smaller body built and muscle mass than African Americans and they may not be considered equivalent to them. Using the four variable MDRD equation for GFR stratifications yielded a smaller number of patients, $8(3 \%)$ as opposed to $16(5.9 \%)$, with an estimated GFR less than $60 \mathrm{ml} / \mathrm{min} / 1.73 \mathrm{~m}^{2}$ compared to the standardized Cockcroft-Gault formula. In the NHANES III study, the prevalence of individuals with an estimated GFR less than $60 \mathrm{ml} / \mathrm{min} / 1.73 \mathrm{~m}^{2}$ according to the MDRD formula was $4.5 \%$ compared to $7 \%$ when using the standardized Cockroft-Gault formula [1].

In spite of the small number of individuals who participated in our study, it gives comparable number of CKD patients as extrapolated from studies performed in the US, Europe and Australia [1-4]. If the present numbers reflect the picture of the whole country, approximately 3-4 million individuals might have some degree of renal impairment. Sudanese health care institutions may not be able to support the heavy economic burden of providing renal replacement therapy (RRT) to all patients who need it. All Sudanese parties involved in this issue should begin an orchestrated effort to approach the problem of CKD.

Age above 50 years and low educational level were the only two factors that remained significantly associated with CKD in multivariate analysis. Low education may predispose to reluctance and noncompliance with medical care. Although other factors, like tobacco consumption [11] and obesity [12] may confer an increased risk for CKD, their effect was not significant in our study participants.

Given the considerable prevalence of hypertension in the HyDRIT study (27\%), the level of unawareness was high (69.6\%) [13]. Among the 14 individuals identified to have CKD, eight subjects were aware of their hypertension status and seven were on antihypertensive medication, but none had a controlled blood pressure of less than 130/80 mmHg. For patients with CKD aggressive goals are currently recommended and antihypertensive therapy is given for both renal protection and cardiovascular protection, since CKD is associated with a marked increase in cardiovascular risk [14]. A reduction in blood pressure to less than $130 / 80 \mathrm{mmHg}$ is recommended as per the Seventh Joint National Committee and the K/DOQI Clinical Practice Guidelines [15, 16].
The prevalence of DM among screened individuals was $5.1 \%$. This figure is well above the WHO estimate of $3.4 \%$ in Sudan [17]. Among diabetics, $42.9 \%$ were unaware of their diabetic status. Almost half of those with a prior diagnosis of DM had their blood sugars controlled to less than $160 \mathrm{mg} / \mathrm{dl}$ by pharmacologic and nonpharmacologic measures. The significant prevalence of DM is in conformity with that of overweight and obesity in our sample $(45.8 \%)$. Eight $(57.1 \%)$ of the diabetics were also hypertensive but none had their blood pressure controlled to less than $130 / 80 \mathrm{mmHg}$. The currently recommended goal blood pressure is less than 130/80 $\mathrm{mmHg}$ in all patients with DM [16]. Promoting healthy life-style changes including weight reduction should help in lowering the prevalence of DM, hypertension and their serious consequences in this population. DM is the most common cause of new patients requiring renal replacement therapy in the industrialized world, accounting for approximately 45, 36 and 22\% of cases in the US, Germany and Australia, respectively [18]. In contradistinction to developed countries, chronic glomerulonephritis and interstitial nephritis are believed to be the principal causes of CKD in developing countries [19]. Despite the considerable prevalence of DM in our sample $(5.1 \%)$, only $13.3 \%$ of patients with CKD had DM. This may indicate a more significant contribution by glomerulonephropathies to the causation of CKD, or simply reflect that the number of participants in our study was not high enough to detect such a relationship.

\section{Study limitations}

The results in this pilot study should be taken with caution since the survey included a small number of paients belonging to a subset of the Sudanese community, and may not reflect the situation in the whole country.

\section{Conclusion}

To conclude, the prevalence of CKD in the study population seems to be comparable to other countries. The only identified independent risk factors were age above 50 years and low-educational level.

\section{Acknowledgment}

We are grateful for the unlimited support of the Medical Services Administration of the Sudan Police Headquarters and its chief; Prof Abdelateef Ashmaig. We thank Lt Colonel Abdel Azeem Alsanosi for his invaluable assistance in coordinating the fieldwork and Lt Colonel Idris Abdalla and his team for their dedicated laboratory support. We also extend our thanks to Dr. Ahlam Alshikeiri for her helpful hints in designing the questionnaire of this study. 


\section{References}

1. Coresh J, Astor BC, Greene T, Eknoyan G, Levey AS. Prevalence of chronic kidney disease and decreased kidney function in the adult US population: Third National Health and Nutrition Examination Survey. Am J Kidney Dis. 2003;41(1):1-12.

2. Chadban SJ, Briganti EM, Kerr PG, Dunstan DW, Welborn TA, Zimmet PZ, Atkins RC. Prevalence of kidney damage in Australian adults: the AusDiab Kidney Study. J Am Soc Nephrol. 2003;14(7 Suppl 2):S131-8.

3. Iseki K. The Okinawa Screening Program. J Am Soc Nephrol. 2003;14(7 Suppl 2):S127-30.

4. Hillege HL, Janssen WM, Bak AA, Diercks GF, Grobbee DE, Crijns HJ, Van Gilst WH, De Zeeuw D, De Jong PE; Prevend Study Group. Microalbuminuria is common, also in a non-diabetic, non-hypertensive population, and an independent indicator of cardiovascular risk factors and cardiovascular morbidity. J Intern Med. 2001;249(6):519-26.

5. Naicker S. End-stage renal disease in sub-Saharan and South Africa. Kidney Int Suppl. 2003 Feb;(83):S119-22.

6. Manjunath G, Tighiouart H, Ibrahim H, MacLeod B, Salem DN, Griffith JL, Coresh J, Levey AS, Sarnak MJ. Level of kidney function as a risk factor for atherosclerotic cardiovascular outcomes in the community. J Am Coll Cardiol. 2003;41(1):47-55.

7. Go AS, Chertow GM, Fan D, McCulloch CE, Hsu CY. Chronic kidney disease and the risks of death, cardiovascular events, and hospitalization. N Engl J Med. 2004;351(13):1296-305.

8. Report of the Expert Committee on the Diagnosis and Classification of Diabetes Mellitus. Diabetes Care. 1997;20(7):1183-97.

9. National Kidney Foundation. K/DOQI clinical practice guidelines for chronic kidney disease: evaluation, classification, and stratification. Am J Kidney Dis. 2002;39(2 Suppl 1):S1-266.

10. Stevens LA, Coresh J, Greene T, Levey AS. Assessing kidney function: measured and estimated glomerular filtration rate. N Engl J Med. 2006 ;354(23):2473-83.

11. Ejerblad E, Fored CM, Lindblad P, Fryzek J, Dickman PW, Elinder CG, McLaughlin JK, Nyren O. Association between smoking and chronic renal failure in a nationwide population-based case-control study. J Am Soc Nephrol. 2004; 15(8):2178-85.

12. Hsu CY, McCulloch CE, Iribarren C, Darbinian J, Go AS. Body mass index and risk for end-stage renal disease. Ann Intern Med. 2006;144(1):21-8.
13. Abu-Aisha H, Elhassan EAM, Khamis AH, AbuElmaali A. Hypertension and obesity in police forces households in Khartoum, Sudan: A pilot report - part of the "Police Forces Hypertension, Diabetes, Renal Insufficiency, and Thyroid Derangements (HyDRIT) Study", Sudan. Sudanese Journal of Public Health. 2008;3(1):17-25.

14. Sarnak MJ, Levey AS, Schoolwerth AC, Coresh J, Culleton B, Hamm LL, McCullough PA, Kasiske BL, Kelepouris E, Klag MJ, Parfrey P, Pfeffer M, Raij L, Spinosa DJ, Wilson PW; American Heart Association Councils on Kidney in Cardiovascular Disease, High Blood Pressure Research, Clinical Cardiology, and Epidemiology and Prevention. Kidney disease as a risk factor for development of cardiovascular disease: a statement from the American Heart Association Councils on Kidney in Cardiovascular Disease, High Blood Pressure Research, Clinical Cardiology, and Epidemiology and Prevention. Circulation. 2003;108(17):2154-69.

15. Chobanian AV, Bakris GL, Black HR, Cushman WC, Green LA, Izzo JL Jr, Jones DW, Materson BJ, Oparil S, Wright JT Jr, Roccella EJ; National Heart, Lung, and Blood Institute Joint National Committee on Prevention, Detection, Evaluation, and Treatment of High Blood Pressure; National High Blood Pressure Education Program Coordinating Committee. The Seventh Report of the Joint National Committee on Prevention, Detection, Evaluation, and Treatment of High Blood Pressure: the JNC 7 report. JAMA. 2003;289(19):2560-72.

16. Kidney Disease Outcomes Quality Initiative (K/ DOQI). K/DOQI clinical practice guidelines on hypertension and antihypertensive agents in chronic kidney disease. Am J Kidney Dis. 2004;43(5 Suppl 1):S1-290.

17. World Health Organization and Sudan Federal Ministry of Health. Joint Annual Report: 2004. Geneva: World Health Organization; 2004. 78p.

18. Collins AJ, Kasiske B, Herzog C, Chen SC, Everson S, Constantini E, Grimm R, McBean M, Xue J, Chavers B, Matas A, Manning W, Louis T, Pan W, Liu J, Li S, Roberts T, Dalleska F, Snyder J, Ebben J, Frazier E, Sheets D, Johnson R, Li S, Dunning S, Berrini D, Guo H, Solid C, Arko C, Daniels F, Wang X, Forrest B, Gilbertson D, St Peter W, Frederick P, Eggers P, Agodoa L. Excerpts from the United States Renal Data System 2003 Annual Data Report: atlas of end-stage renal disease in the United States. Am J Kidney Dis. 2003;42(6 Suppl 5):A5-7, S1-230.

19. Barsoum RS. Chronic kidney disease in the developing world. N Engl J Med. 2006;354(10):997-9. 